\title{
Research on Factors Affecting the Risk of Ischemic Cerebrovascular Disease in Postmenopausal Women Based on the Social-Ecological Model
}

\section{Chun-Jun Yang}

Tianjin Medical University General Hospital

Dong-Mei Wang

Tianjin Medical University General Hospital

Tong Wang

Tianjin Medical University General Hospital

Ying Song ( $\square$ songy8886@163.com )

Tianjin Medical University General Hospital

\section{Research Article}

Keywords: postmenopausal women, ischemic cardiovascular disease, social ecological model

Posted Date: February 22nd, 2022

DOI: https://doi.org/10.21203/rs.3.rs-1358251/v1

License: (a) (i) This work is licensed under a Creative Commons Attribution 4.0 International License. Read Full License 


\section{Abstract \\ Objective}

Based on the social-ecological model, this study aimed to comprehensively explore factors affecting the risk of ischemic cerebrovascular disease (ICVD) in postmenopausal women to provide theoretical bases for further prevention and intervention for postmenopausal women.

\section{Methods}

Postmenopausal women who underwent medical examinations in one health-checkup agency in Tianjin from May 2015 to October 2015 were enrolled in this study. The ICVD 10-year Risk Assesment Form developed by the research team of the National "Tenth Five-Year Plan" research project was used to assess the factors affecting the risk of ICVD. Based on the social-ecological model, multiple types of scales were used to comprehensively explore the factors associated with ICVD in postmenopausal women.

\section{Results}

300 valid questionnaires were obtained, with an effective rate of $92.0 \%$. The maximum age of the subjects was 74 years old, the minimum age was 44 years old, and the average age was $62.06 \pm 7.09$ years old. Among them, $58.67 \%$ of the subjects only obtained high-school diploma, $32.67 \%$ obtained college or university diploma, $90.33 \%$ were retirees, $95.33 \%$ were married, $92.33 \%$ experienced the natural menopause, $93.33 \%$ lived in urban or suburban areas, and $1.00 \%$ had a history of breast cancer. Multivariate logistic regression analysis suggested that monthly income, parity, exposure to second-hand or third-hand smoke, easy access to healthy food, physical activities, depression, Type D personality, social support and environmental factors were associated with the risk of ICVD in postmenopausal women $(P<0.05)$. Among them, easy access to healthy food $(O R=0.242)$, social support $(O R=0.861)$ and environmental factors $(O R=0.866)$ were the protective factors from ICVD. Parity $(O R=3.795)$, exposure to second-hand or third-hand smoke $(O R=2.886)$, depression $(O R=1.193)$, and Type $D$ personality $(O R=1.148)$ were risk factors of ICVD.

\section{Conclusions}

For postmenopausal women, in the future, in addition to prevention and management of the conventional risks, the conditions of their mentality and social support should be paid attention to, at the same time, and if they can, try to choose a good community environment to live in, which could better reduce the incidence and mortality of ICVD in postmenopausal women. 


\section{Introduction}

With the development of economy and society, people's diets and lifestyles have changed accordingly, especially the high-fat, high-salt and high-sugar diet and sedentary lifestyle, resulting in the increased incidence and mortality of cardiovascular diseases year by year (1-4). For postmenopausal women, a lack of estrogen that has a protective effect on the cardiovascular system is associated with a significantly increased risk of cardiovascular disease (5-10). Therefore, it has become a crucial problem in today's society to explore the factors affecting the risk of cardiovascular disease in postmenopausal women. Social ecosystem theory (SET) is a new theoretical model based on the relationship between human behavior and social environment, which consists of micro-level system of individuals, meso-level system of family, work world or other social groups, and macro-level system of environment, community, etc., and stresses the comprehensive influences of individual factors, natural environment and social environment on human health (11-13). However, currently, researches in our country mostly focus on sociodemographic characteristics and laboratory testing at the micro-level, and ignore the psychological factors at the micro-level, the social supports at the meso-level, and the community environment at the macro-level, which also affects the incidence of cardiovascular disease. The research team from the national "Tenth Five-Year Plan" research project of "Coronary Heart Disease and Stroke Comprehensive Risk Assessment and Intervention Program Research" takes into account that our country, as a developing country, is a country with relatively low incidence of coronary heart disease and relatively high incidence of stroke, and if the coronary heart disease risk assessment model from the western country is directly used to predict the risk of cardiovascular disease in the Chinese population, the prediction results may be inaccurate, and thus this research team used the follow-up data of 17,329 subjects to build a predictive model, and named the the combined endpoint of coronary heart disease and ischemic stroke as ischemic cardiovascular disease (ICVD) (14). Our present study, based on SET, aimed to explore the risk factors of ICVD in postmenopausal women from the above three levels. It is expected to provide a theoretical basis for prevention and intervention of ICVD in postmenopausal women in the future.

\section{Materials And Methods}

\section{1 subjects}

Postmenopausal women who underwent medical examinations in one health-checkup agency in Tianjin from May 2015 to October 2015 were enrolled in this study.

Inclusion criteria: 1) patients had menopause for more than one year; 2) patients did not have medical history of cardiovascular disease, such as coronary heart disease, ischemic stroke, etc.; 3) patients was able to complete the questionnaire independently.

Exclusion criteria: 1) patients was unable to participate in daily physical activity; 2) patients had a medical history of psychosis; 3) patients was unwilling to participate in this study; 4) patients did not complete the questionnaire for various reasons. 


\subsection{Calculation of sample size}

According to the requirements of logistic regression analysis, the sample size is generally 20 to 30 times the number of variables. The number of variables in our present study was 12 . Considering the drop out of the samples and the invalid questionnaire, we set the drop out rate as $10 \%$ to obtain the sample size greater than 264 . Thus, we finally determined to include 300 cases in this study.

\subsection{Theoretical framework}

SET is designed to explore the relationship between the social ecological environment and human behavior, and how they interact and influence each other. This theory focuses on individuals in the social ecological system, and believes that interaction and mutual-influence of individuals and the environment are dynamic and coadapted, emphasizes that the social ecological environment is of great significance for the exploration and interpretation of human behavior, and to a certain extent, provides a more comprehensive theoretical basis for social work.

This theoretical model consists of micro-level system, meso-level system and macro-level system. The micro-level system refers to individuals who exist independently in the social ecological environment, with physical, psychological, and social attributes. The meso-level system refers to small-scale organizations that have an impact on individuals, including families, colleagues, or other social groups. The macro-level system refers to a social system that is larger than the meso-level system, mainly including environment, culture, community, etc. These three-level systems are always interacting and influencing each other. Therefore, in order to understand and solve problems more comprehensively, we should explore the underlying causes of human behavior from multiple levels and perspectives.

\subsection{Research tools}

\subsection{1 basic questionnaire on general data}

A self-designed basic questionnaire for general information, such as age, working condition, education, marriage status, (body mass index) BMI, medical history, blood pressure, total cholesterol and triglycerides, was used.

\subsubsection{Ischemic Cardiovascular Disease (ICVD) 10-year Risk Assessment Form}

The "Ischemia Cardiovascular Disease (ICVD) 10-year Risk Assessment Form" (14) developed by the research team of the national "Tenth Five-Year Plan" research project was used to do the risk assessment of ICVD in postmenopausal women, including 6 risk factors: age, systolic blood pressure, total cholesterol, body mass index (BMI), diabetes mellitus (DM) and smoking. Each risk factor was given different risk scores according to different conditions of cases, and finally the sum of risk scores of 6 factors was calculated for each case. According to the absolute risk, the samples were divided into two groups: the low-risk group (absolute risk $<10 \%$ ) and the high-risk group (absolute risk $\geq 10 \%$ ). 


\subsubsection{Self-rating depression scale}

The self-rating depression scale (15) developed by W.K.Zung in 1965 was used to assess the subjective feelings, including 20 items, 10 of which were scored in reverse. A 4-level scoring of 1 to 4 points was used. Finally, the sum of the scores of 20 items was calculated to obtain the original total score. Standard score $=$ original total score $\times 1.25$.

\subsubsection{D-type personality scale}

The D-type personality scale (DS14) with good reliability and validity (16) was developed by Denollet J, a Dutch scholar, and translated and revised by Yu XN and Zhang JX from the Chinese Academy of Sciences. The scale consists of 2 dimensions of social inhibition and negative emotions. The questionnaire used a 5-level scoring of 0 to 4 points, of which 2 items were scored in reverse. The score of one dimension was the sum of the scores of the items in this dimension. The total score of the scale was the sum of the scores of all items in this scale. The social inhibition score and the negative emotions score were both greater than 10 points at the same time, which can be diagnosed as Type $D$ personality.

\subsubsection{Social Support Rating Scale}

Social Support Rating Scale (SSRS) with good reliability and validity (17) was developed led by Xiao SY in 1986. Cronbach 'a of the the total score is 0.92 , and Cronbach 'a of each item score is $0.89 \sim 0.94$. The scale has 10 items and consists of 3 dimensions, including objective support, subjective support and the rate of social support utilization. The score of one dimension is the sum of the scores of the items in this dimension, and the total score of social support is the sum of the scores of the three dimensions. The higher the total score is, the more social support is and the less social isolation is.

\subsubsection{Abbreviated - Neighborhood Environment Walkability Scale}

The Abbreviated - Neighborhood Environment Walkability Scale (ANEWS) (18) amended by Zhou Rena from the Fudan university in 2011 consists of 5 dimensions, including 17 items. The questionnaire uses a 5-level scoring from 1 to 5 points. The score of one dimension is the sum of scores of items in this dimension, and the total score of the scale is the sum of the scores of all items. The higher the total score is, the better the walking environment is. Cronbach's a of the scale is 0.807 , the intra-group correlation coefficient (ICC) is 0.945 , and the Spearman correlation coefficient is 0.721 .

\subsubsection{Women's Health Initiative Physical Activity Questionnaire}

The Women's Health Initiative Physical Activity Questionnaire (WHI-PAQ) (19) developed by Anne-Marie Meyer, a American scholar, and translated and revised by Yang CJ, mainly consists of two parts, including physical exercise and housework, with a total of 8 items, such as walking, light, moderate and heavy physical exercise, housework, garden activities, and sitting and sleeping time. The formula is: total energy consumption $=$ (weekly activity frequency $\times$ minutes per time $\times$ corresponding metabolic equivalent $) /($ 60 minutes/hour). WHI-PAQ classifies the intensity of exercise into 3 levels according to total energy 
consumption, including low-intensity exercise ( $<500 \mathrm{MET} \times \min \times$ wk $(-1))$, medium-intensity exercise (500 1200 MET $\times$ min $\times$ wk (-1)) and High-intensity exercise (>1200 MET $\times$ min $\times$ wk $(-1))$. The test-retest reliability of the scale is 0.950 , and each dimension is $0.957-0.669$. The Spearman rank correlation coefficient of overall standard validity is 0.884 , the content validity index (CVI) is 0.923 , and the content validity ratio (CVR) is 0.846 , with good reliability and validity.

\subsection{Methods for performing the questionnaire survey}

The researcher conducted a questionnaire survey for postmenopausal women who met the inclusion criteria. Before filling out the questionnaire, based on the guidelines, how to fill out and what to note was introduced by the researchers. After completing the questionnaires, the researchers checked the submitted questionnaires on the spot. For the questionnaires with the missing items, remedial measures were took in time, and then the researchers took them back without any missing items after checking again.

\subsection{Statistical analysis}

SPSS 18.0 statistical software was used for data entry and processing, and double entry and validation were used. If the quantitative data conformed to the normal distribution, the mean \pm standard deviation (SD) was used, and the difference between groups was analyzed by t-test. If quantitative data did not conform to a normal distribution, the median and inter-quartile range were used to describe the data, and the difference between groups was analyzed by rank-sum test. For qualitative data, frequency and percentage was used to describe the data, and the difference between groups was analyzed by Chisquare test. Binary Logistic regression analysis was used to analyze and explore the factors affecting the occurrence of ICVD in postmenopausal women, and $\mathrm{P}<0.05$ in two sides was considered statistically significant.

\section{Results}

\subsection{Socio-demographic data of the enrolled postmenopausal women}

A total of 326 questionnaires were collected. After the questionnaires with incomplete data were removed, 300 valid questionnaires were obtained, with an effective rate of $92.0 \%$. The maximum age of the subjects was 74 years old, the minimum age was 44 years old, and the average age was $62.06 \pm 7.09$ years old. Among them, $58.67 \%$ of the subjects only obtained high-school diploma, $32.67 \%$ obtained college or university diploma, $90.33 \%$ were retirees, $95.33 \%$ were married, $92.33 \%$ experienced the natural menopause, $93.33 \%$ lived in urban or suburban areas, and $1.00 \%$ had a history of breast cancer.

\subsection{Statistical analysis of risk factors of ICVD in postmenopausal women}

\subsubsection{Independent sample $t$ test}


Independent sample t-test analysis indicated that there were significant differences in monthly income, gravidity, parity, physical activities, depression, Type D personality, social supports and environment score between the low-risk group and the high-risk group $(\mathrm{P}<0.05)($ Table 1$)$.

\subsubsection{Chi-square test}

The $\chi^{2}$ test analysis suggested there were significant differences in working conditions, whether to be exposed to second-hand or third-hand smoke, whether to easily buy healthy food, and whether to participate in lectures on cardiovascular disease between the low-risk group and the high-risk group $(\mathrm{P}<0.05)$ (Table 2).

\subsubsection{Multivariate logistic regression analysis}

The high-risk and low-risk groups as the dependent variables ( 0 for the low-risk group, 1 for the high-risk group), and the above described factors with statistical significance as independent variables were given the assignments (Table 3), and the Enter method was used to include variables. Then, the multi-factor logistic regression analysis was carried out (Table 4). The results suggested that monthly income, parity, whether to be exposed to second-hand smoke or third-hand smoke, whether to easily to buy healthy food, physical activities, depression, Type D personality, social supports and environment all were associated with the risk of ICVD in postmenopausal women $(P<0.05)$. OR $>1$ indicated that the factors were positively correlated with ICVD, and made the risk of ICVD increase. OR $<1$ indicated that the factors were negatively correlated with ICVD, and the factors had effects of preventing the occurrence of ICVD. Therefore, easy access to healthy food, social supports and environment were protective factors for ICVD, while parity, exposure to second-hand or third-hand smoke, depression, and Type D personality were risk factors for ICVD. In addition, the OR values of monthly income and physical activities were close to 1 , which suggesting that these two factors were rarely correlated with ICVD in postmenopausal women.

\section{Discussion}

Based on the SET, a multi-dimensional research and analysis was performed, and we found that the micro-level system, meso-level system and macro-level system in the social ecological model all had an impact on the risk of ICVD in postmenopausal women.

\subsection{Analysis of factors affecting the risk of ICVD in postmenopausal women in the micro-level system of the social ecological model}

The multivariate logistic analysis revealed that the OR values of parity, exposure to second (third)- hand smoke, depression, and Type D personality were 3.795 (95\%Cl: 1.657-8.689), 2.886 (95\%Cl: 1.087 7.659), 1.193 (95\% Cl: 1.072 1.328), and 1.148 (95\% Cl: 1.044 1.264), respectively, which were all risk factors for ICVD in postmenopausal women.

Some studies suggested that parity was remarkably associated with the risk of carotid atherosclerotic plaque, and also associated with a decrease of HDL-C and an increase of the ratio of blood 
glucose/insulin $(20,21)$. In addition, multiple parturition could increase the risk of metabolic syndrome in women, and thus, it might result in the increased risk of ICVD in postmenopausal women to a certain extent $(22,23)$. Active or passive smoking, as a bad habit of life, has been found to be an independent risk factor for cardiovascular disease and also an important risk factor for adult death in our country (24-27). The harmfulness of depression and Type $D$ personality as negative psychological emotions have been confirmed by researches. A longitudinal study of middle-aged women implied that depression was an important risk factor for stroke (28). In addition, it was also confirmed that depression, as a negative emotion, can increase the incidence and mortality of coronary heart disease and stroke $(29,30)$. Type D personality is directly related to cardiovascular disease. Type $D$ personality can cause the synergistic activation of the sympathetic adrenal system and hypothalamic-pituitary-adrenal axis to generate a strong salivary cortisol response which might be directly related to the occurrence of cardiovascular disease $(31,32)$. In addition, Type D personality can activate the tumor necrosis factor alpha (TNF-alpha) and its receptors in patients with ischemic heart disease, causing the dysfunction of the human immune system $(33,34)$. The OR value of physical activity was 0.999 (95\% Cl: $0.998-0.999)$, and the OR value of monthly income was 1.001 (95\% Cl: 1.000-1.001), indicating that these two factors had little association with the occurrence of ICVD. Although studies suggested that exercise was not only an effective and safe way to relieve menopausal symptoms in postmenopausal women (35), but also reduced the incidence of cardiovascular disease in postmenopausal women (36-38), the effect of physical activities on the occurrence of ICVD was not obvious in our study, which might result from the other factors that had significant effects on the occurrence of ICVD. Different studies have different opinions on the relationship between monthly income and the risk of cardiovascular disease. Some studies believed that economic income was not significantly associated with the risk of cardiovascular diseases(39), but some studies suggested the negative correlation between income and cardiovascular disease, and it would be reversed at a certain age, yet, with different opinions on the inflection point. One Study indicated that the risk of cardiovascular disease was negatively correlated with economic income in people aged 50-64, while economic income in people older than 64 years old did not have an influence on the risk of cardiovascular disease (40). However, another study implied that the inflection point was 74 years old (41). The results of a survey on dietary nutrients of residents in China suggestted that with the increase of income, more and more people tend to have a poor dietary structure of high protein, high fat and low grain (42), which is likely to exacerbate the occurrence of cardiovascular disease. Therefore, the relationship between monthly income and cardiovascular disease is necessary to be further explored in the future.

\subsection{Analysis of factors affecting the risk of ICVD in postmenopausal women in the meso-level system of the social ecological model}

The OR value of social support in the meso-level system was 0.861 (95\% Cl: $0.789-0.941)$, indicating that social support was a protective factor for ICVD in postmenopausal women. Social support includes not only subjective emotional supports, such as understanding and other pleasant positive emotions, but also objective and practical supports, such as material assistance etc. What's more, good utilization of social support and the correct way of seeking help constitute a complete social support system. 
Postmenopausal women with poor social support are more likely to be at high risk of ICVD. It have also been evidenced that lack of social support can aggravate the cardiovascular response of individuals under stress (43), while adequate social support has a buffer effect on the cardiovascular response caused by stress (44), which can only make a small increase in the blood pressure and heart rate of the population, thereby more easily returning to the normal level.

\subsection{Analysis of factors affecting the risk of ICVD in postmenopausal women in the macro-level system of the social ecological model}

The OR value of the environmental factor in the macro-level system was 0.866 (95\%Cl: $0.801-0.937$ ), implying that it was a protective factor. That exploration of the environment as a possible factor affecting the risk of cardiovascular disease was the first attempt in China, and our results suggested that good community living environment, including perfect living facilities, flat roads, good greening, good lighting conditions, and good and safe transportation, was a protective factor for postmenopausal women from ICVD, and might slow down the occurrence and development of ICVD to a certain extent, for which the reason might be that good community living environment could increase the convenience of going out, thereby increasing the level of physical activities of individuals (45-47). This also provides a theoretical basis for the urban planning and environmental design in the future. Based on combining environmental hygiene with epidemiology, comprehensively considering the epidemiological characteristics of the disease is one of development trends in the future.

In addition, there are some limitations in our study. The ample size is small and only from one center. No long term follow up is performed. In the future, it is necessary to do the further study on this topic using multiple centers and large sample size, and do a long term follow up for those person whom finished the questionnaire.

In summary, the factors affecting the risk of ICVD in postmenopausal women include not only common micro-factors, but also psychological factors, social factors and environmental factors that are easily ignored. For the special group of postmenopausal women, in the future, in addition to prevention and control of the conventional risks, the conditions of their mentality and social support should be paid attention to, at the same time, and if they can, try to choose a good community environment to live in, in order to better reduce the incidence and mortality of ICVD in postmenopausal women.

\section{Declarations}

Ethics approval and consent to participate: This study was conducted in accordance with the declaration of Helsinki. This study was conducted with approval from the Ethics Committee of Tianjin Medical University General Hospital. Written informed consent was obtained from the participants.

Consent for publication : obtained from the participants. 
Availability of data and materials: The datasets used and/or analysed during the current study available from the corresponding author on reasonable request.

Competing interests: all authors declare they have no conflict of interests.

Funding: This research received no specific grant from any funding agency in the public, commercial, or not-for-profit sectors.

Authors' contributions: 1) Chun-Jun Yang, Ying Song, Substantial contributions to the conception and design of the work; And 2) Chun-Jun Yang, Dong-Mei Wang, Tong Wang, Ying Song, the acquisition, analysis, and interpretation of data for the work; And 3) Chun-Jun Yang, drafting the work; AND 4) Ying Song, revising it critically for important intellectual content; AND 5) Chun-Jun Yang, Dong-Mei Wang, Tong Wang, Ying Song, final approval of the version to be published; AND 6) Chun-Jun Yang, Dong-Mei Wang, Tong Wang, Ying Song, agreement to be accountable for all aspects of the work in ensuring that questions related to the accuracy or integrity of any part of the work are appropriately investigated and resolved.

\section{Acknowledgements: N/A}

\section{References}

1. Doewes RI, Gharibian G, Zadeh FA, Zaman BA, Vahdat S, Akhavan-Sigari R. An updated systematic review on the effects of aerobic exercise on human blood lipid profile. Curr Probl Cardiol. (2022):101108. doi: 10.1016/j.cpcardiol.2022.101108. Epub ahead of print.

2. Soh YC, Yap KH, McGrattan A, Yasin S, Reidpath D, Siervo M, et al. Protocol for a systematic review assessing the measurement of dietary sodium intake among adults with elevated blood pressure. BMJ Open. (2022) 12:e052175. dor: 10.1136/bmjopen-2021-052175.

3. Bergwall S, Johansson A, Sonestedt E, Acosta S. High versus low-added sugar consumption for the primary prevention of cardiovascular disease. Cochrane Database Syst Rev. (2022) 1:CD013320. doi: 10.1002/14651858.CD013320.pub2.

4. Guo X, Xu X, Gao J, Wang W, Hou W, Wu X, et al. Twenty-Year Trajectory-Patterns of Percentage Energy From Dietary Fat vs. Carbohydrate Throughout Adult Life and Associations With CardioMetabolic Disease and All-Cause Mortality. Front Nutr. (2021) 8:701188. doi: 10.3389/fnut.2021.701188.

5. Crescioli C. The Role of Estrogens and Vitamin D in Cardiomyocyte Protection: A Female Perspective. Biomolecules. (2021) 11:1815. doi: 10.3390/biom11121815.

6. Maluleke TT, Millen AME, Michel FS. The effects of estrogen deficiency and aging on myocardial deformation and motion in normotensive female rats. Menopause. (2021) 29:89-95. doi: 10.1097/GME.0000000000001884. 
7. Prabakaran S, Vitter S, Lundberg G. Cardiovascular Disease in Women Update: Ischemia, Diagnostic Testing and Menopause Hormone Therapy. Endocr Pract. (2021) S1530-891X(21)01291-X. doi: 10.1016/j.eprac.2021.10.007.

8. Abramson BL, Black DR, Christakis MK, Fortier M, Wolfman W. Guideline No. 422e: Menopause and Cardiovascular Disease. J Obstet Gynaecol Can. (2021) 43:1438-1443.e1. doi: 10.1016/j.jogc.2021.09.010.

9. Knowlton AA, Lee AR. Estrogen and the cardiovascular system. Pharmacol Ther. (2012) 135:54-70. doi: 10.1016/j.pharmthera.2012.03.007.

10. Murphy E. Estrogen signaling and cardiovascular disease. Circ Res. (2011) 109: 687-696. doi: 10.1161/CIRCRESAHA.110.236687.

11. Freak-Poli R, Ryan J, Neumann JT, Tonkin A, Reid CM, Woods RL, et al. Social isolation, social support and loneliness as predictors of cardiovascular disease incidence and mortality. BMC Geriatr. (2021) 21:711. doi: 10.1186/s12877-021-02602-2.

12. Jilani MH, Javed Z, Yahya T, Valero-Elizondo J, Khan SU, Kash B, et al. Social Determinants of Health and Cardiovascular Disease: Current State and Future Directions Towards Healthcare Equity. Curr Atheroscler Rep. (2021) 23:55. doi: 10.1007/s11883-021-00949-w.

13. Zastrow $\mathrm{CH}$, Ashman KC. Understanding human behavior and the social environment. 6th edition, translated by Shi HL. Beijing: China Renmin University Press, (2004) :15-20.

14. the national "10th Five-Year Plan" research group of "comprehensive risk assessment and intervention plan for coronary heart disease and cerebral apoplexy". A study on evaluation of the risk of ischemic cardiovascular diseases in Chinese and the development of simplified tools for the evaluation. CHINESE JOURNAL OF CARDIOLOGY (2003) 31:893-901. doi:10.3760/j:issn:02533758.2003.12.005

15. Zhang ZJ. Manual of behavioral medicine scales. Beijing: Chinese medical multimedia press, (2005) :213-223.

16. Yu XN, Zhang JX. Application of Type D Personality Scale (DS14) in Chinese College Students. CHINESE MENTAL HEALTH JOURNAL (2006) 20:313-316. doi:10.3321/j.issn:10006729.2006.05.011

17. Wang XD, Wang XL, Ma H. Manual of Mental Health Rating Scales (Revised Version). Chinese Mental Health Journal (1999): :86-88.

18. Zhou RN, Fu H, Luo JF, Li Y. Evaluation on reliability and validity of Chinese Walkable Environment Scale for urban community residents. CHINESE JOURNAL OF PUBLIC HEALTH (2011) 27:841-843

19. Yang CJ, Zhang Q. Reliability and Validity of the Chinese Version Women's Health Initiative Physical Activity Questionnaire for Postmenopausal Women. Chinese General Practice (2016) 19:88-91. doi: 10.3969/j.issn.1007-9572.2016.01.018

20. Cortés YI, Parikh N, Allison MA, Criqui MH, Suder N, Barinas-Mitchell E, et al. Women's Reproductive History and Pre-Clinical Peripheral Arterial Disease in Late Life: The San Diego Population Study. J Womens Health (Larchmt). (2019) 28:1105-1115. doi: 10.1089/jwh.2018.7080. 
21. Sun K, Lin D, Qiling F, Li F, Qi Y, Feng W, et al. Number of parity is associated with low-grade albuminuria in middle-aged and elderly Chinese women. BMC Womens Health. (2019) 19:117. doi: 10.1186/s12905-019-0814-2.

22. Xie Q, Xu H, Wan Q. Correlation between parity and metabolic syndrome in Chinese women aged 40 years and older: the Reaction study. BMC Endocr Disord. (2021) 21:236. doi: 10.1186/s12902-02100902-7.

23. Shi M, Zhou X, Zheng C, Pan Y. The association between parity and metabolic syndrome and its components in normal-weight postmenopausal women in China. BMC Endocr Disord. (2021) 21:8. doi: 10.1186/s12902-020-00674-6.

24. Kondo T, Nakano Y, Adachi S, Murohara T. Effects of Tobacco Smoking on Cardiovascular Disease. Circ J. (2019) 83:1980-1985. doi: 10.1253/circj.CJ-19-0323.

25. DiGiacomo SI, Jazayeri MA, Barua RS, Ambrose JA. Environmental Tobacco Smoke and Cardiovascular Disease. Int J Environ Res Public Health. (2018) 16:96. doi: 10.3390/ijerph16010096.

26. Khoramdad M, Vahedian-Azimi A, Karimi L, Rahimi-Bashar F, Amini H, Sahebkar A. Association between passive smoking and cardiovascular disease: A systematic review and meta-analysis. IUBMB Life. (2020) 72:677-686. doi: 10.1002/iub.2207.

27. Pan B, Jin X, Jun L, Qiu S, Zheng Q, Pan M. The relationship between smoking and stroke: A metaanalysis. Medicine (Baltimore). (2019) 98:e14872. doi: 10.1097/MD.0000000000014872.

28. Liu X, Cheng C, Liu Z, Fan W, Liu C, Liu Y. Longitudinal assessment of anxiety/depression rates and their related predictive factors in acute ischemic stroke patients: A 36-month follow-up study. Medicine (Baltimore). (2021) 100:e28022. doi: 10.1097/MD.0000000000028022.

29. Diamond PR, Dysch L, Daniels J. Health anxiety in stroke survivors: a cross-sectional study on the prevalence of health anxiety in stroke survivors and its impact on quality of life. Disabil Rehabil. (2022) :1-7. doi: 10.1080/09638288.2021.2022778. Epub ahead of print.

30. Sun WJ, Xu L, Chan WM, Lam TH, Schooling CM. Are depressive symptoms associated with cardiovascular mortality among older Chinese: a cohort study of 64,000 people in Hong Kong? Am J Geriatr Psychiatry. (2013) 21:1107-1115. doi: 10.1016/j.jagp.2013.01.048.

31. Raykh OI, Sumin AN, Korok EV. The Influence of Personality Type D on Cardiovascular Prognosis in Patients After Coronary Artery Bypass Grafting: Data from a 5-Year-Follow-up Study. Int J Behav Med. (2021) :1-11. doi: 10.1007/s12529-021-09992-y. Epub ahead of print.

32. Enatescu VR, Cozma D, Tint D, Enatescu I, Simu M, Giurgi-Oncu C, et al. The Relationship Between Type D Personality and the Complexity of Coronary Artery Disease. Neuropsychiatr Dis Treat. (2021) 17:809-820. doi: 10.2147/NDT.S303644.

33. Conraads VM, Denollet J, De Clerck LS, Stevens WJ, Bridts C, Vrints CJ. Type D personality is associated with increased levels of tumour necrosis factor (TNF)-alpha and TNF-alpha receptors in chronic heart failure. Int J Cardiol. (2006) 113:34-8. doi: 10.1016/j.ijcard.2005.10.013.

34. Mommersteeg PM, Pelle AJ, Ramakers C, Szabó BM, Denollet J, Kupper N. Type D personality and course of health status over 18 months in outpatients with heart failure: multiple mediating 
inflammatory biomarkers. Brain Behav Immun. (2012) 26:301-10. doi: 10.1016/j.bbi.2011.09.010.

35. Moradpour F, Koushkie Jahromi M, Fooladchang M, Rezaei R, Sayar Khorasani MR. Association between physical activity, cardiorespiratory fitness, and body composition with menopausal symptoms in early postmenopausal women. Menopause. (2020) 27:230-237. doi:

10.1097/GME.0000000000001441. Erratum in: Menopause. (2021) 28:602. Morardpour, Fatemeh (corrected to Moradpour, Fatemeh). PMID: 31999652.

36. Manojlović M, Protić-Gava B, Maksimović N, Šćepanović T, Poček S, Roklicer R, et al. Effects of Combined Resistance and Aerobic Training on Arterial Stiffness in Postmenopausal Women: A Systematic Review. Int J Environ Res Public Health. (2021) 18:9450. doi: 10.3390/ijerph18189450.

37. Yılmaz S, Arslan I, Yengil Taci D. The effect of physical activity and depressive mood on menopausal symptoms in postmenopausal women. Int J Clin Pract. (2021) 75:e14247. doi: 10.1111/ijcp.14247.

38. Kim JH, Ha MS, Ha SM, Kim DY. Aquatic Exercise Positively Affects Physiological Frailty among Postmenopausal Women: A Randomized Controlled Clinical Trial. Healthcare (Basel). (2021) 9:409. doi: $10.3390 /$ healthcare9040409.

39. Wu SP, Hua RR, Wang WZ, Jiang B, Du XL, Bao QJ. Association between Income and the Level of Knowledge, Attitude and Behavior among Elderly Cardiovascular Disease Patients in Beijing. CHINESE JOURNAL OF PREVENTION AND CONTROL OF CHRONIC NON-COMMUNICABLE DISEASES. (2009) 17:444-447.

40. Avendano M, Glymour MM. Stroke disparities in older Americans: is wealth a more powerful indicator of risk than income and education? Stroke (2008) 39:1533-1540. doi:

10.1161/STROKEAHA.107.490383.

41. Avendano M, Kawachi I, Van Lenthe F, Boshuizen HC, Mackenbach JP, Van den Bos GA, et al. Socioeconomic status and stroke incidence in the US elderly: the role of risk factors in the EPESE study. Stroke. (2006) 37:1368-73. doi: 10.1161/01.STR.0000221702.75002.66.

42. Xia X, Wang Q, Chen PP, Wu WC, Li WJ. Influence of income level on nutrition intake of older patients with cardiovascular disease. JOURNAL OF ZHENGZHOU UNIVERSITY(MEDICAL SCIENCES) (2007) 42:1174-1177. doi:10.3969/j.issn.1671-6825.2007.06.054

43. Gallagher S, Creaven AM, Howard S, Ginty AT, Whittaker AC. Gratitude, social support and cardiovascular reactivity to acute psychological stress. Biol Psychol. (2021) 162:108090. doi: 10.1016/j.biopsycho.2021.108090.

44. Gallagher S, O'Súilleabháin PS, Smith MA. The cardiovascular response to acute psychological stress is related to subjectively giving and receiving social support. Int J Psychophysiol. (2021) 164:95-102. doi: 10.1016/j.jpsycho.2021.03.004.

45. Cao N, Hao Z, Niu L, Zhang N, Zhu H, Bao H, et al. The Impact of Risk Factor Control on HealthRelated Quality of Life in Individuals with High Cardiovascular Disease Risk: A Cross-sectional Study Based on EQ-5D Utility Scores in Inner Mongolia, China. J Epidemiol Glob Health. (2022) doi: 10.1007/s44197-021-00028-y. Epub ahead of print. 
46. Dalstrom M, Guth B, Lizer C, Zimmermann K, Khare M. Supporting a rural wellness intervention through assessing and mapping rural physical activity environments. Prev Med Rep. (2021) 24:101567. doi: 10.1016/j.pmedr.2021.101567.

47. Soltani S, Saraf-Bank S, Basirat R, Salehi-Abargouei A, Mohammadifard N, Sadeghi M, et al. Community-based cardiovascular disease prevention programmes and cardiovascular risk factors: a systematic review and meta-analysis. Public Health. (2021) 200:59-70. doi: 10.1016/j.puhe.2021.09.006.

\section{Tables}

Table 1

Independent sample $t$ test for the risk of ICVD

\begin{tabular}{|c|c|c|c|c|}
\hline Factors & $\begin{array}{l}\text { Low-risk group }(n=207) \\
\bar{x} \pm s\end{array}$ & $\begin{array}{l}\text { High-risk group }(n=93) \\
\qquad \bar{x} \pm s\end{array}$ & $t$ & $P$ \\
\hline TG & $1.63 \pm 1.31$ & $1.74 \pm 1.40$ & -0.68 & 0.505 \\
\hline Monthly income & $2931.40 \pm 859.91$ & $3230.75 \pm 1004.59$ & -2.65 & $0.009 * \star$ \\
\hline Age of menarche & $14.39 \pm 2.03$ & $14.82 \pm 1.79$ & -1.74 & 0.083 \\
\hline Age of first delivery & $27.37 \pm 3.08$ & $26.73 \pm 2.44$ & 1.77 & 0.077 \\
\hline Age of menopause & $49.76 \pm 3.74$ & $50.59 \pm 4.50$ & -1.67 & 0.095 \\
\hline Parity & $1.56 \pm 0.84$ & $1.96 \pm 0.82$ & -3.61 & $0.000 * \star \star$ \\
\hline Gravidity & $1.19 \pm 0.49$ & $1.75 \pm 0.71$ & -7.93 & $0.000^{* \star *}$ \\
\hline Physical activity & $4268.43 \pm 1681.15$ & $2325.43 \pm 939.13$ & 10.43 & $0.000 * * *$ \\
\hline Depression & $41.05 \pm 5.88$ & $50.48 \pm 6.06$ & -12.72 & $0.000 * * *$ \\
\hline Type D personality & $11.52 \pm 6.19$ & $19.03 \pm 6.43$ & -9.61 & $0.000 * * *$ \\
\hline Social support & $35.34 \pm 6.38$ & $27.65 \pm 4.49$ & 10.51 & $0.000 * \star *$ \\
\hline Environment & $58.44 \pm 9.29$ & $53.35 \pm 4.75$ & 5.09 & $0.000 * \star *$ \\
\hline
\end{tabular}


Table 2

Chi-square test for the risk of ICVD in postmenopausal women

\begin{tabular}{|c|c|c|c|c|c|}
\hline factors & & $\begin{array}{l}\text { Low-risk } \\
\text { group }(n= \\
207)\end{array}$ & $\begin{array}{l}\text { High-risk } \\
\text { group }(\mathrm{n}= \\
\text { 93) }\end{array}$ & $x^{2}$ & $P$ \\
\hline \multirow[t]{3}{*}{ Working conditions } & On job & 26 & 1 & 14.23 & $0.001 * *$ \\
\hline & Retirement & 180 & 91 & & \\
\hline & Without job & 1 & 1 & & \\
\hline \multirow[t]{4}{*}{ Education } & $\begin{array}{l}\text { Primary school or } \\
\text { without }\end{array}$ & 8 & 2 & 3.06 & 0.383 \\
\hline & High school & 120 & 56 & & \\
\hline & College or university & 79 & 34 & & \\
\hline & Graduate school & 0 & 1 & & \\
\hline \multirow[t]{3}{*}{ Marriage status } & Being married & 198 & 88 & 4.54 & 0.104 \\
\hline & Being widowed & 5 & 5 & & \\
\hline & Being divorced & 4 & 0 & & \\
\hline \multirow[t]{2}{*}{ Ways of menopause } & Natural & 189 & 88 & 1.06 & 0.303 \\
\hline & Surgical & 18 & 5 & & \\
\hline \multirow[t]{5}{*}{ Types of health care } & $\begin{array}{l}\text { Basic health } \\
\text { insurance }\end{array}$ & 197 & 89 & 6.21 & 0.184 \\
\hline & $\begin{array}{l}\text { The rural } \\
\text { cooperative medical } \\
\text { care }\end{array}$ & 3 & 0 & & \\
\hline & $\begin{array}{l}\text { Out-of-pocket } \\
\text { Medical services }\end{array}$ & 2 & 0 & & \\
\hline & $\begin{array}{l}\text { Medical services at } \\
\text { state expense }\end{array}$ & 5 & 3 & & \\
\hline & $\begin{array}{l}\text { Commercial health } \\
\text { insurance }\end{array}$ & 0 & 1 & & \\
\hline \multirow[t]{3}{*}{ Residence } & Rural & 4 & 0 & 3.33 & 0.189 \\
\hline & Urban & 12 & 4 & & \\
\hline & Suburban & 191 & 89 & & \\
\hline Drinking & Yes & 11 & 1 & 3.74 & 0.053 \\
\hline
\end{tabular}

Note: $*: P<0.05 ;{ }^{* * P}<0.01 ; * * * P<0.001$ 


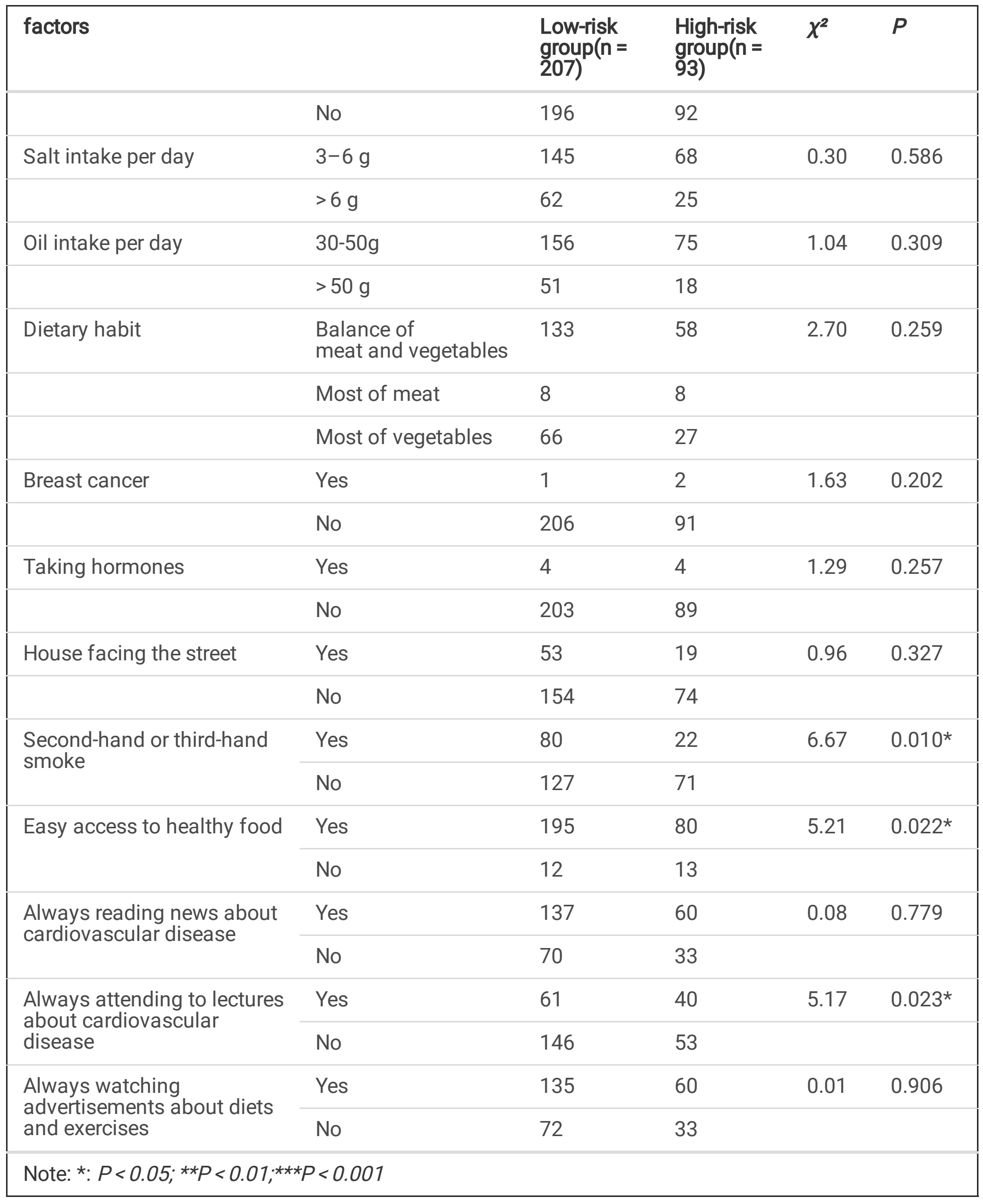


Table 3

assignments of variables affecting the risk of ICVD in menopause women

\begin{tabular}{ll}
\hline Variables & Assignments \\
\hline Low- or high-risk cases & 0 for low-risk cases; 1 for high-risk cases \\
\hline Monthly income & Actual value \\
\hline Gravidity & Actual value \\
\hline Parity & Actual value \\
\hline Physical activity & Actual value \\
\hline Depression scoring & Actual value \\
\hline Type D personality scoring & Actual value \\
\hline Social support scoring & Actual value \\
\hline Environment scoring & Actual value \\
\hline Working conditions & 1 for on job; 2 for unemployed \\
\hline Whether to be exposed to second- or third-hand smoke & 1 for yes; 2 for no \\
\hline Whether to easily buy healthy food & 1 for yes; 2 for no \\
\hline Whether to attend lectures about cardiovascular disease & 1 for yes; 2 for no \\
\hline
\end{tabular}

Table 4

multivariate logistic regression analysis of factors affecting the risk of ICVD in postmenopausal women

\begin{tabular}{|llllll|}
\hline Factors & $\boldsymbol{\beta}$ & Wald $\chi^{2}$ value & OR & OR(95\%Cl & $\boldsymbol{P}$ \\
\hline Monthly income & 0.001 & 6.238 & 1.001 & $1.000 \sim 1.001$ & $0.013^{\star}$ \\
\hline Parity & 1.334 & 9.553 & 3.795 & $1.657 \sim 8.689$ & $0.002^{\star \star}$ \\
\hline Second-hand or third-hand smoke & 1.060 & 4.528 & 2.886 & $1.087 \sim 7.659$ & $0.033^{\star}$ \\
\hline Easy access to healthy food & -1.417 & 3.875 & 0.242 & $0.059 \sim 0.994$ & $0.049^{\star}$ \\
\hline Physical activity & -0.001 & 21.875 & 0.999 & $0.998 \sim 0.999$ & $0.000^{\star \star \star}$ \\
\hline Depression & 0.177 & 10.468 & 1.193 & $1.072 \sim 1.328$ & $0.001^{\star \star}$ \\
\hline Type D personality & 0.138 & 8.013 & 1.148 & $1.044 \sim 1.264$ & $0.005^{\star \star}$ \\
\hline Social support & -0.149 & 10.996 & 0.861 & $0.789 \sim 0.941$ & $0.001^{\star \star}$ \\
\hline Environment & -0.143 & 13.033 & 0.866 & $0.801 \sim 0.937$ & $0.000^{\star \star \star}$ \\
\hline Note: $*$ : $P<0.05 ; * * P<0.01 ; * \star * P<0.001$ & & & & \\
\hline
\end{tabular}

